\title{
Some implication of environmental pesticides pollution on malaria control in Ghana
}

\author{
D. K. Essumang* \\ Department of Chemistry, University of Cape Coast, Cape Coast, Ghana
}

\begin{abstract}
The exposures of anopheles mosquito (Anopheles labranchiae) larvae to sub-lethal doses of pesticides have resulted in some selective resistance of the vector to some insecticides. The study determined the levels of pyrethroid insecticide, Allethrin 1, Allethrin 2, Lambda-cyhalothrin, deltamethrin and some organochlorine pesticides; p,p'-DDT, and o,p'-DDD in water bodies and lagoons (mosquitoes' breeding environment) in malaria endemic areas in some communities in Ghana. Water samples collected from mosquitoes' breeding sites were analyzed for pyrethroid insecticide and some organochlorine pesticides using standard methods. The levels recorded in this study (0.001- $0.009 \mathrm{ppm})$ were an indication of the presence of the mosquito insecticide in the breeding environment of the vector. The abuse of pesticides into the environment may have serious implications on malaria control due to resistance of disease causing vectors to insecticides. It is now time for malaria control strategies to integrate environmental pollution control measures in their quest to roll back malaria. This study though limited, serves as a wakeup call for all to be good stewards of the environment to ensure good health for all.
\end{abstract}

\section{Introduction}

The burden of malaria is said to be increasing, especially in subSaharan Africa, because of drug and insecticide resistance as well as environmental changes [1,2]. Malaria is said to be a disease that threatens the lives and livelihoods of about 500 million people worldwide especially Africans and exerts a huge health burden such that, it has been associated with the continued under-development of the entire African continent [3-6]. The World Health Organization's report on malaria for 2014 estimates that about 3.3 billion people are at risk of malaria, of which 1.2 billion are at high risk. In high-risk areas, more than one malaria case occurs per 1000 population [7]. According to the report, there were an estimated 198 million cases of malaria worldwide (ranging between 124-283 million) in 2013, and an estimated 584000 deaths (ranging between $367000-755000$ ). Unfortunately 90 percent of all malaria deaths reported occurred only in Africa [7].

In 2013, an estimated 437000 African children died before their fifth birthday due to malaria. Globally, the disease caused an estimated 453000 under-five deaths in 2013 [7]. Environmental mismanagement can have dire consequence on the spread of malaria. The anopheles mosquito (Anopheles labranchiae) is known to be the leading transmitter of malaria (Plasmodium falciparum) in the tropics. Changing environmental conditions have altered mosquito breeding sites in water bodies, lagoons, wetlands and which has had a significant influence on their insecticide resistance [8]. As a result, effective malaria control cannot go without effective environmental pollution control. World Health Organization recently, reported of emerging parasite resistance to antimalarial medicines and mosquito resistance to insecticides and if left unaddressed, could render some of the malaria control tools currently being used ineffective and may trigger a rise in global malaria mortality. According to the report, between 2010 and 2013, 53 countries globally have reported mosquito resistance to at least one insecticide and 41 have two or more insecticide classes. The most commonly resistant pesticide reported are pyrethroids, which is the most frequently used insecticide in malaria vector control [7]. Indeed, environmental approaches to malaria control, though promising, has seen very little application in Africa for a long period of time. Environmental management for malaria control does not require any special skill, but rather just keeping clean surroundings. The only thing that is currently lacking in sub-Saharan Africa where they are needed most is how to put structures in place to ensure environmental compliance [8].

The emergence and proliferation of all kinds of chemicals used for several purposes disturbs the environment and may exert an influence on the resistance of mosquitoes to insecticides. It is known that, changes in the environment, whether naturally or through anthropogenic sources, changes the ecological balance and context within which hosts or vectors and parasites that bring disease breed [9]. There is extensive use of pesticides in most developing countries including Ghana (Pesticide abuse) to control pest in order to ensure food security; unfortunately, most of these pesticides get leached into water bodies and wetland areas where mosquitoes and other vectors breed. The presence of sub-lethal levels of pesticides at where mosquitoes breed could make them resistant to insecticides in their adult stage. Thus, rendering current malaria control tools somewhat ineffective due to the use of the same pesticides [7], thereby adding another dimension to malaria control.

Even though tremendous efforts have been put in malaria control strategies in Africa and for that matter Ghana, not much seems to

Correspondence to: Essumang DK, Department of Chemistry, University of Cape Coast, Cape Coast, Ghana, E-mail: kofiessumang@yahoo.com

Key words: Anopheles labranchiae, pyrethroids, organochlorines, environmental pollution, insecticide resistance

Received: January 04, 2015; Accepted: February 10, 2015; Published: February 14,2015 
have been achieved. There is still the search for realistic approaches to malaria control [10]. This therefore demands commitment of all sectors to rally forces commensurate with the magnitude of the problem, while aiming at realistic objectives. It is worth noting that controlling environmental pollution alone can go a long way in our quest to control malaria in Africa.

Ghana's effort to control malaria began in the 1950s, which aimed at reducing significantly the malaria disease burden in order for it not to become a public health problem. It was noted, that the health sector alone could not control malaria effectively and therefore, multiple strategies were pursued with other related sectors. Though, several interventions were applied, malaria continued to be the leading cause of morbidity (illness) in the country [11]. Some of the strategies included residual insecticide application on mosquitoes, mass chemoprophylaxis with Pyrimethamine medicated salt and improvement of drainage systems [11]. The only environmental component therein was the improvement of the drainage systems but had nothing to do with the chemical composition of the water present. The study determined the levels of pyrethroid insecticide, Allethrin 1, Allethrin 2, Lambda-cyhalothrin, deltamethrin and Organochlorines pesticides; p,p'-DDT, and o,p'-DDD in water bodies and lagoons (mosquitoes' breeding environment) in malaria endemic areas in some communities in Ghana.

\section{Materials and method}

\section{Qualitative analysis of the active ingredient in 15 mosquito insecticides}

An initial study was done to ascertain the active ingredient in 15 popular mosquito insecticides on the Ghanaian market. Though the Ghana Standard Authority require only allenthrin as the active ingredient in mosquito insecticides it is likely due to competition on the market others may add some banned ingredient.

\section{Sample preparation}

About $5 \mathrm{~g}$ of each sample was dissolved in methanol in tight fitting Erlenmeyer flasks and labeled according to their brand names.

\section{Crude extraction}

The methanol-sample mixture was shaken thoroughly and allowed to stand over-night. After 24 hours of extraction, each solution was filtered through a Whatman's No. 45 filter paper to obtain filtrates of the extract. The clear solution was concentrated by evaporating the methanol to about 1-3 mL [12] using the Evaporator.

\section{Preparation of Thin Layer Chromatography (TLC) plate}

About $75 \mathrm{~g}$ of silica gel was weigh into a flask with a tight lid. A volume of $150 \mathrm{~mL}$ of distilled water was added and shaken vigorously till a uniform paste was obtained. The paste was poured on the spreader and glass plates of uniform thickness which were initially cleaned with acetone were arranged under the spreader for spreading to occur (thin smear or layer on the plates). These plates were left to dry under atmospheric conditions (air dry) [12].

\section{Spotting}

The TLC plates were activated between the temperatures of $80^{\circ} \mathrm{C}$ and $100^{\circ} \mathrm{C}$ to expel moisture from the plate. This was done for about 15 to $30 \mathrm{~min}$ and subsequently cooled at room temperature. A pin was used to make a spot $2.0 \mathrm{~cm}$ from the bottom of the plate which was noted as the origin. The desired solvent front travel was also ruled at $10 \mathrm{~cm}$ from the original points with their corresponding labeling above the $10 \mathrm{~cm}$ line. A thin capillary tube was used to pick few micro liters of the sample and spotted on an original point. On the next original point was a standard solution of organchlorine spotted followed by another sample respectively. Also, the active ingredient, D-Allethrin was spotted alongside the samples. The plates were left for about 5 minutes for spots to dry up [12].

\section{Development of chromatogram}

A solvent system made of $80 \mathrm{~mL}$ of $95 \% \mathrm{v} / \mathrm{v} \mathrm{n}$-hexane was mixed with $20 \mathrm{~mL}$ of $99.9 \%$ ethyl acetate in a chromatographic tank covered and allowed to stand for about 30 minutes. After this time, spotted plates were placed in the tank in a vertical position with the spotted side touching the mobile phase (solvent system). The tank was tightly closed with its lid and allowed to stand till the mobile phase moved to just below the $10 \mathrm{~cm}$ mark made at top of the plate before it was taken out of the tank [12].

\section{Collection of water samples}

Fifty water samples were collected along different points of the Butia lagoon, Sekondi-Takoradi (Oil city of Ghana). Another twenty water samples were also collected from the River Tano at Techiman in the Brong Ahafo region of Ghana (Figure 1). The samples were collected in large dark amber bottles which had been well cleaned, dried and well labeled.

The samples were collected from areas where there were large numbers of mosquito larvae present in the water. After the samples were collected, they were transported to the laboratories of the chemistry department at the Ghana Atomic Energy Commission in an ice chest and stored three days at $4^{\circ} \mathrm{C}$ until the extraction was done.

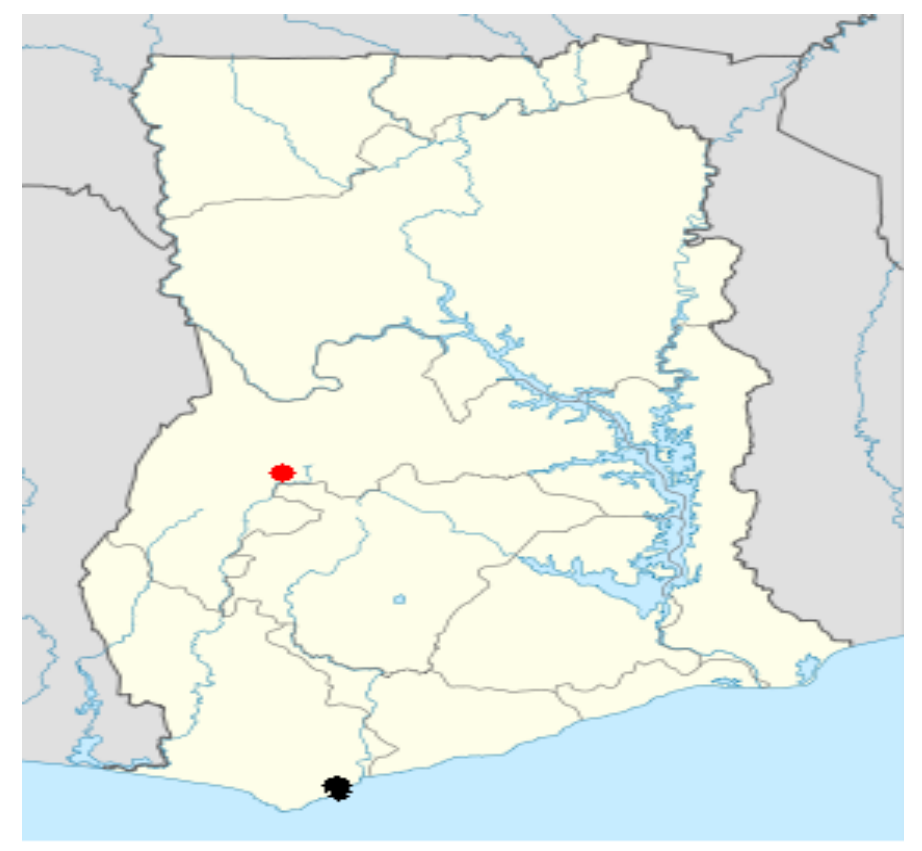

\section{- Sekondi-Takoradi (Btia Lagoon) * Techiman(Tano River)}

Figure 1. Map showing the sampling site. 


\section{Extraction of pesticides from the water samples}

The method of extraction used was the USEPA method 3510 [13] for extracting multi-residue pesticides in water. Hundred milliliters of the sample was measured and transferred into a $500 \mathrm{~mL}$ separatory funnel. About $50 \mathrm{~mL}$ of methanol and $50 \mathrm{~mL}$ of chloroform were each measured and added to the sample in the separatory funnel, (that is $[1: 1 \mathrm{v} / \mathrm{v}]$ methanol, chloroform). The mixture was carefully shaken and the phases were allowed to separate. The chloroform layer which was non-polar and contained the organic pollutant was collected. The upper layer, that is the methanol layer or aqueous layer was polar and was discarded. The extraction was repeated with two $50 \mathrm{~mL}$ portions of methanol and chloroform. Twenty grams of anhydrous sodium sulphate was measured and the chloroform layer was dried over anhydrous sodium sulphate. The dried samples were then concentrated to $5 \mathrm{~mL}$ using rotary evaporator. This procedure was repeated for each sample.

\section{Clean up}

For each of the samples a solid phase extraction cartridge packed with $\mathrm{C}^{18}$ adsorbent, was conditioned with methanol and the $5 \mathrm{~mL}$ dried samples were injected through the SPE cartridge with a syringe. The $\mathrm{C}^{18}$ adsorbent has a high affinity for the organic compounds and as such trapped all the organic compounds in the samples. The SPE cartridges were each eluted with $7 \mathrm{~mL}$ of analytical grade (95\%) hexane into 10 $\mathrm{mL}$ glass vials and further concentrated using a stream nitrogen gas to about $2 \mathrm{~mL}$. The Final extracts were appropriately labeled and stored in a refrigerator $\left(\right.$ at $\left.4^{\circ} \mathrm{C}\right)$ awaiting gas chromatography [14].

\section{Gas chromatographic analysis}

For the GC determination $1.0 \mu \mathrm{L}$ of the sample was injected into the Gas chromatograph. The organochlorines were detected and quantified using EC detector. Quantization was made by comparing with the standards.

A Varian 3800 gas chromatograph equipped with a ${ }^{63} \mathrm{Ni}$ electroncapture detector (ECD) and capillary column $(30 \mathrm{~m} \times 0.25 \mathrm{~mm}$, i.d. x $0.25 \mu \mathrm{m}$ film thickness) was used. A $1.0 \mu \mathrm{L}$ of each sample extract was injected into the column. The operating conditions were: injector temperature $225^{\circ} \mathrm{C}$, EC detector temperature $300^{\circ} \mathrm{C}$. Temperature programming was employed and Table 1 show the conditions used. Selective ion monitoring was employed in the quantification of the analytes by comparing with the base peak of the standards. The limit of detection (LOD) used was $0.001 \mathrm{mg} / \mathrm{L}$.

\section{Results and discussion}

\section{Qualitative analysis of the active ingredient in 15 mosquito insecticides}

Preliminary qualitative studies of the active ingredient present in most of the mosquito insecticides on the Ghanaian market was done and the results are presented in table 2 . All the 15 tested insecticides had the required active ingredient of allenthrin as required by the Ghana Standard Authority. However, there were quite a few that had

Table 1. Conditions for temperature programming.

\begin{tabular}{|c|c|c|c|}
\hline Temp $\left({ }^{\circ} \mathbf{C}\right)$ & Rate $\left({ }^{\circ} \mathbf{C} / \mathbf{m i n}\right)$ & Hold (min) & Total (min) \\
\hline 60 & 0.0 & 2.00 & 2.00 \\
\hline 180 & 25.0 & 1.00 & 7.80 \\
\hline 300 & 5.0 & 0.00 & 31.80 \\
\hline
\end{tabular}

Table 2. The presence (+) and absence (-) of the Active ingredient in 15 different mosquito insecticides.

\begin{tabular}{|c|c|c|c|}
\hline \multirow{2}{*}{$\begin{array}{c}\text { Brand of mosquito } \\
\text { insecticide }\end{array}$} & Some common active ingredient in mosquito insecticides \\
\cline { 2 - 4 } & D-Allethrin & S-2 & DDT \\
\hline 1 & + & - & - \\
\hline 2 & + & - & - \\
\hline 3 & + & + & - \\
\hline 4 & + & - & - \\
\hline 5 & + & + & - \\
\hline 6 & + & - & - \\
\hline 7 & + & - & - \\
\hline 8 & + & - & - \\
\hline 9 & + & + & - \\
\hline 10 & + & - & + \\
\hline 11 & + & + & - \\
\hline 12 & + & - & - \\
\hline 13 & + & - & + \\
\hline 14 & + & + & - \\
\hline 15 & + & - & - \\
\hline
\end{tabular}

NB: The Brand names have been withheld. S-2=Avenger S-2 Insecticide

Table 3. Organochlorines identified in samples and their mean concentrations (ppm) at the Butia Lagoon.

\begin{tabular}{|c|c|c|c|}
\hline Sample ID & $\begin{array}{c}\text { Organochlorines } \\
\text { identified }\end{array}$ & $\begin{array}{c}\text { Concentration } \\
\text { (ppm) }\end{array}$ & Retention time \\
\hline A & p,p'-DDT & 0.001 & 23.149 \\
\hline B & o,p'-DDD & 0.001 & 20.611 \\
\hline & p,p'-DDT & 0.001 & 23.144 \\
\hline C & p,p'-DDT & 0.001 & 23.149 \\
\hline
\end{tabular}

S-2 and DDT present which are banned chemicals in Ghana. It is therefore worth noting that some organochlorines are still present in some brands of mosquito insecticides in Ghana.

\section{Levels of the pesticides in the water bodies}

The concentrations of persistent organic pollutants identified in the Butia Lagoon using the Varian 3800 Gas Chromatograph are shown in Table 3. The major organochlorines identified were metabolites or breakdown products of DDT (dichlorordiphenyltriphenylethane), that is p,p'-DDT and o,p'-DDD (p,p'-Dichlorodiphenyldichloroethane).

In sample $\mathrm{A}$, taken from north of the lagoon and sample $\mathrm{C}$ from where the lagoon joins the sea at New Takoradi, p,p'-DDT was identified as the main contaminant with a concentration of $0.001 \mathrm{ppm}$. In the case of sample B, both p,p'-DDT and o,p'-DDD were identified with concentrations of $0.001 \mathrm{ppm}$ each. This was the mid-section of the lagoon which is surrounded by factories. The metabolites of DDT are more persistent than the parent compound. Though these results confirm the presence and concentrations of DDT and its metabolite it does not adequately determine its toxicology. Little data is available that exclusively addresses water contamination in the Butia lagoon. The concentrations of DDT and it's metabolites from the results obtained were relatively low, and according to literature this may not pose any immediate threat to human, animal or plant health. However DDT and related compounds are extremely persistent in the environment. This persistence, combined with a high partition coefficient $(\log$ Kow $=4.89$ 6.91) provides the necessary conditions for DDT to bioconcentrate in organisms. WHO [15] suggest that higher accumulations of DDT at higher trophic levels in aquatic systems results from a tendency of organisms at higher trophic levels to accumulate more DDT directly from the water, rather than by biomagnifications. 
Some synthetic pyrethroids were also found in the samples from the Butia Lagoon. In sample A, allethrin1 (0.002 ppm), allethrin2 (0.003 ppm), lamba-cyhal (0.001 ppm) and deltamethrin $(0.003 \mathrm{ppm})$ were found. In sample B, allethrin $1(0.003 \mathrm{ppm})$, allethrin $2(0.003$ ppm), lamba-cyhal $(0.001 \mathrm{ppm})$ and deltamethrin $(0.003 \mathrm{ppm})$ were found (Table 4). Sample C, also recorded an appreciable levels of the pyrethroids. Synthetic pyrethroids do not accumulate and persist in the body; moreover the concentrations found were too low to pose any serious human health problems. Similarly, synthetic pyrethroids were also identified in the Tano River at Techiman at slightly higher concentration in sample C (Table 5) compared to Butia Lagoon. The possible reason is that, Techiman is a well know farming community which uses a lot of pesticides.

Table 4. Pyrethroids identified in samples and their mean concentrations from the Butia Lagoon.

\begin{tabular}{|c|c|c|c|}
\hline Sample ID & Pyrethroids identified & Concentration (ppm) & Retention Time \\
\hline A & Allethrin 1 & 0.002 & 18.310 \\
\hline & Allethrin 2 & 0.003 & 18.352 \\
\hline & lamba-cyhal & 0.001 & 26.413 \\
\hline & deltamethrin & 0.003 & 32.966 \\
\hline B & allethrin 1 & 0.003 & 18.310 \\
\hline & allethrin 2 & 0.003 & 18.353 \\
\hline & lamba-cyhal & 0.001 & 26.412 \\
\hline & deltamethrin & 0.003 & 32.969 \\
\hline C & Allethrin 1 & 0.002 & 18.310 \\
\hline & Allethrin 2 & 0.002 & 18.352 \\
\hline & lamba-cyhal & 0.001 & 26.413 \\
\hline & Deltamethrin & 0.002 & 32.966 \\
\hline
\end{tabular}

Table 5. Pyrethroids identified in samples and their mean concentrations from the Tano River at Techiman.

\begin{tabular}{|c|c|c|c|}
\hline Sample ID & Pyrethroids identified & Concentration (ppm) & Retention time \\
\hline A & Allethrin 1 & $<0.001$ & 18.310 \\
\hline & Allethrin 2 & $<0.001$ & 18.352 \\
\hline B & Allethrin 1 & 0.003 & 18.310 \\
\hline & Allethrin 2 & 0.004 & 18.352 \\
\hline C & Allethrin 1 & 0.007 & 18.310 \\
\hline & Allethrin 2 & 0.009 & 18.352 \\
\hline
\end{tabular}

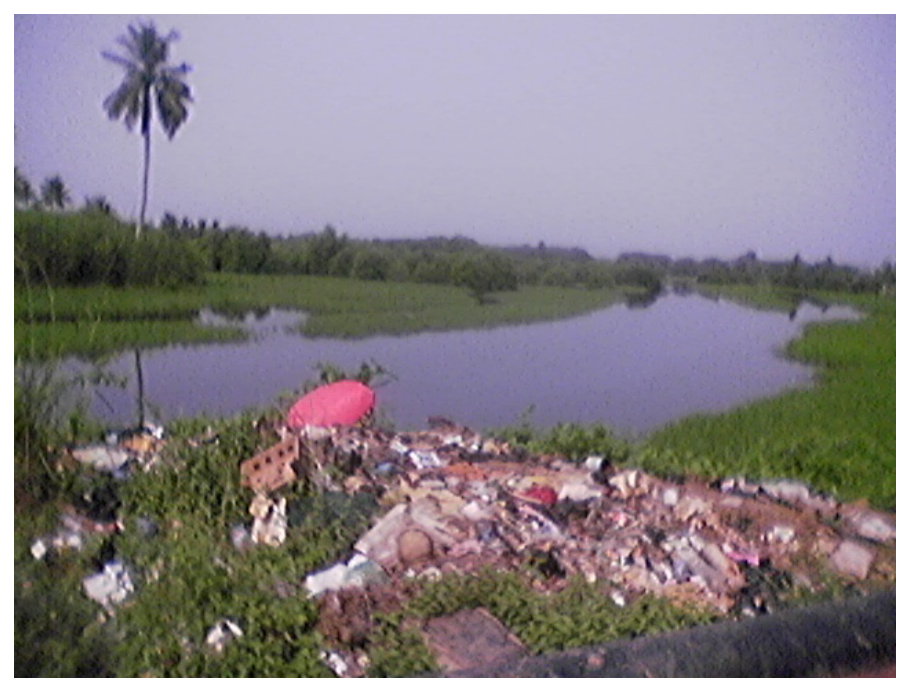

Figure 2. Photograph of Butia Lagoon close to domestic waste dump.
When pesticides are found in water supplies, they normally are not present in high enough concentrations to cause acute health effects such as chemical burns, nausea, or convulsions. Instead, they typically occur in trace levels, and the concern is primarily for their potential of causing chronic human health problems [16].

\section{Implication for Mosquito resistance to insecticide}

The presence of insecticides in the water environment does not only affect water quality but has implication for malaria control as well. Yadouleton et al., [17] reported in a study that, the improper use of insecticide to control pests has exerted huge selection pressure on mosquito larval population. This has resulted, according to the report, in the emergence of insecticide resistance in malaria vectors. The study provided further evidence on the contribution of the overuse of insecticide in agriculture to the widespread emergence of insecticide resistance in Anopheles species [17]. Yadouleton and his team collected Anopheles larvae from vegetable farms and reared to adults in insectaria and subjected the adult mosquitoes' to insecticideimpregnated papers and noted the resistance [17]. However, this study looked at the background characteristics of the larvae from the water where they breed. The type of chemicals therein, may have had an effect on their resistance at the adult stage as noted in a report by WHO [7]. This has given further evidence of how environmental pesticide pollution may have contributed to increasing resistance of mosquitoes to pyrethroids, the most frequently used insecticide in malaria vector control [7]. The result indicates that most of the water bodies analyzed had sub-lethal levels of most of the mosquito insecticides, especially the pyrethroids. This indeed may make the mosquito larvae adaptive to these chemicals at such early stage of their life. It is worth noting that, controlling environmental pollution alone could go a long way in our quest to control malaria in Africa.

Similar concerns were raised by Bowman et al. [18] and Roberts et al. [19], that through runoff, DDT from areas sprayed with the insecticide got accumulated in natural water bodies and that could affect pesticide resistant in mosquitoes [20]. Ranson et al. were of the view that the selection of resistant mosquitoes is as a result of the increase use of pyrethroid insecticides in malaria vector control [21]. The sub-lethal levels obtained in this study (0.001- $0.009 \mathrm{ppm})$ in the breeding environment of mosquito's larvae may be enough to contribute to selective resistance at an adult stage [20].

The contribution of environmental pollution to insecticide resistance by Anopheles labranchiae has not been fully utilized in most malaria control strategies. The places where they usually breed have been recognized, but the chemical compositions of the water therein have not been used as means to control malaria. Pyrethroids resistance was reported in Anopheles labranchiae in Côte d'Ivoire [22,23] and later on, many other cases of pyrethroid resistance in Anopheles vectors were detected in West [24], Central [25], Eastern [26] and Southern Africa [27]. It is envisaged from this study, that, the presence of pyrethroid insecticide, Allethrin 1, Allethrin 2, Lambda-cyhalothrin, deltamethrin and Organochlorines, p,p'-DDT, o,p'-DDD at sub-lethal concentrations of 0.001- $0.009 \mathrm{ppm}$ in the breeding environment of mosquito larvae, may play a vital role in the selective resistance at their adult stage via Knock-down resistance (kdr) [28].

The Knock-down resistance $(\mathrm{kdr})$ mutation may be probably responsible for the emergence of selective resistance of Anopheles vectors to DDT and pyrethroids due to sub-lethal concentration of pesticides exposure [28]. The hypothesis of the implication of the $\mathrm{kdr}$ mutation in the emergence of resistance has been confirmed in a study 
by Yadouleton et al. [17] even though minimum level of possible effect was not provided.

In 1993 the first case of pyrethroids resistance in An. gambiae was reported in Africa $[23,25]$. The emergence of pyrethroid resistance in An. gambiae has become of serious concern to the success of malaria control in the last decade [22,23]. Pyrethroids remain the only family of insecticides currently registered for the impregnation of bed-nets, the major control strategy against malaria vectors in Ghana [25,29]. Dieldrin and DDT resistance were reported in Burkina-Faso with populations of An. gambiae [23,25].

It is now time for malaria control strategies to integrate environmental pollution control measures in the quest to roll back malaria. The abuse of pesticides into the environment may have serious implications on resistance of diseases causing vectors to insecticides.

\section{Conclusion}

The persistent organic pollutants found in the samples taken from the Butia lagoon were p,p'-DDT and o,p'-DDD which are both metabolites of DDT. The study revealed that the concentration of the metabolites or breakdown products of DDT found in the Butia lagoon were relatively low, however there is a risk of bioaccumulation in mosquito larvae in these water bodies that may possibly lead to selective resistance. The presence of pyrethroid insecticide, Allethrin 1, Allethrin 2, Lambda-cyhalothrin, deltamethrin also indicate the abuse of mosquito insecticide in the environment and which should be seen as a serious issue in the efforts to roll back malaria. Appreciable levels of the synthetic pyrethroids were determined in both Butia lagoon and the Tano River. This study though limited, serves as a wakeup call for all to be good stewards of the environment to ensure good health for all. Further work to measure mosquitoes resistance to the concentration of pesticides in water bodies is underway and will be reported in due cause.

\section{Acknowledgment}

The author wishes to express his sincere appreciation to all the students who supported this work. Also, to the staff of Centre for Scientific and Industrial Research, (CSIR) Environmental Division (ED), Water Research Institute (WRI) and the Organic Laboratory for their kind assistance in the analysis of the samples. Finally, I wish to thank the government of Ghana for financial assistance.

\section{References}

1. Martinez-Torres D, Chandre F, Williamson MS, Darriet F, Bergé JB, et al. (1998) Molecular characterization of pyrethroid knockdown resistance $(\mathrm{kdr})$ in the major malaria vector Anopheles gambiae s.s. Insect Mol Biol 7: 179-84.

2. Greenwood BM, Fidock DA, Kyle DE, Kappe SH, Alonso PL, et al. (2008) Malaria: progress, perils, and prospects for eradication. J Clin Invest 118: 1266-1276. [Crossref]

3. Snow RW, Craig M, Deichmann U, Marsh K (1999) Estimating mortality, morbidity and disability due to malaria among Africa's non-pregnant population. Bull World Health Organ 77: 624-640. [Crossref]

4. Breman JG, Egan A, Keusch GT (2001) The intolerable burden of malaria: a new look at the numbers. Am J Trop Med Hyg 64: iv-vii. [Crossref]

5. Sachs J, Malaney P (2002) The economic and social burden of malaria. Nature 415: 680-685. [Crossref]

6. Greenwood B, Mutabingwa T (2002) Malaria in 2002. Nature 415: 670-672. [Crossref]

7. World Health Organinisation (2014) Factsheet on the World Malaria Report 2014.

8. Killeen GF, Seyoum A, Knols BG (2004) Rationalizing historical successes of malaria control in Africa in terms of mosquito resource availability management. Am J Trop Med Hyg 71: 87-93. [Crossref]
9. Patz JA, Graczyk TK, Geller N, Vittor AY (2000) Effects of environmental change on emerging parasitic diseases. Int J Parasitol 30: 1395-1405. [Crossref]

10. Nájera JA (2001) Malaria control: achievements, problems and strategies. Parassitologia 43: 1-89. [Crossref]

11. Ghana health service (GHS) (2014), National Malaria Control Programme.

12. Ghana Standard 147: 2007; A manual for the analysis for insecticide.

13. Edgell K, Wesselman R (1989) USEPA Method Study 36 - Sw-846 Methods 8270/3510 GC/MS Method for Semivolatile Organics: Capillary Column Technique Separatory Funnel Liquid-Liquid Extraction. U.S. Environmental Protection Agency, Washington, D.C. EPA/600/4-89/010 (NTIS Pb89190581).

14. US EPA (1989) Evaluation of Sample Extract Cleanup Using Solid-Phase Extraction Cartridges. Project Report, December 1989

15. World Health Organisation (1989). Allethrin: allethrin, d-allethrin, bioallethrin.IPCS international programme on chemical safety, environmental health criteria 87.

16. Trautmann NM, Keith S, Wagenet RJ (2012) Pesticides: Health Effects in Drinking Water: Natural Resources Cornell Cooperative Extension. Pesticide Safety Education Program.

17. Yadouleton AW, Asidi A, Djouaka RF, Braïma J, Agossou CD, et al. (2009) Development of vegetable farming: a cause of the emergence of insecticide resistance in populations of Anopheles gambiae in urban areas of Benin. Malar J 8: 103. [Crossref]

18. Bowman CJ, Kroll KJ, Hemmer MJ, Folmar LC, Denslow ND (2000) Estrogen-induced vitellogenin mRNA and protein in sheepshead minnow (Cyprinodon variegatus). Gen Comp Endocrinol 120: 300-313. [Crossref]

19. Roberts DR, Manguin S, Mouchet J (2000) DDT house spraying and re-emerging malaria. Lancet 356: 330-332. [Crossref]

20. Sereda BL, Meinhardt HR (2005) Contamination of the Water Environment in Malaria Endemic Areas of KwaZulu-Natal, South Africa by DDT and Its Metabolites. Bull Environ Contam Toxicol 75: 538-545

21. Ranson H, N'guessan R, Lines J, Moiroux N, Nkuni Z, et al. (2011) Pyrethroid resistance in African anopheline mosquitoes: what are the implications for malaria control? Trends Parasitol 27: 91-98. [Crossref]

22. Diabate A1, Baldet T, Chandre F, Akoobeto M, Guiguemde TR, et al. (2002) The role of agricultural use of insecticides in resistance to pyrethroids in Anopheles gambiae s.l. in Burkina Faso. Am J Trop Med Hyg 67: 617-622. [Crossref]

23. Diabaté A, Baldet T, Chandre F, Guiguemdé RT, Brengues C, et al. (2002) First report of the kdr mutation in Anopheles gambiae M form from Burkina Faso, west Africa. Parassitologia 44: 157-158. [Crossref]

24. N'Guessan R, Darriet F, Guillet P, Carnevale P, Traore-Lamizana M, et al. (2003) Resistance to carbosulfan in Anopheles gambiae from Ivory Coast, based on reduced sensitivity of acetylcholinesterase. Med Vet Entomol 17: 19-25. [Crossref]

25. Etang J, Manga L, Chandre F, Guillet P, Fondjo E, et al. (2003) Insecticide susceptibility status of Anopheles gambiae s.l. (Diptera: Culicidae) in the Republic of Cameroon. $J$ Med Entomol 40: 491-497. [Crossref]

26. Vulule JM, Beach RF, Atieli FK, MCallister JC, Brogdon WG, et al. (1999). Elevated oxidase and esterase levels associated with permethrin tolerance in Anopheles gambiae from Kenyan villages using permethrin impregnated nets. Med Vet Entomol 13: 239244.

27. Hargreaves K, Koekemoer LL, Brooke BD, Hunt RH, Mthembu J, et al. (2000) Anopheles funestus resistant to pyrethroid insecticides in South Africa. Med Vet Entomol 14: 181-189. [Crossref]

28. Santolamazza F, Etang CM, Barrese J, Dia E, Caccone I, et al. (2008) Distribution of knock-down resistance mutations in Anopheles gambiae molecular forms in west and west-central Africa. Malaria Journal 7: 74. [Crossref]

29. Carnevale P, Robert V, Boudin C, Halna JM, Pazart L, et al. (1988) Control of malaria using mosquito nets impregnated with pyrethroids in Burkina Faso. Bull Soc Pathol Exot Filiales 81: 832-846. [Crossref]

Copyright: (C2015 Essumang DK. This is an open-access article distributed under the terms of the Creative Commons Attribution License, which permits unrestricted use, distribution, and reproduction in any medium, provided the original author and source are credited. 